\title{
ANÁLISE ESTRATÉGICA DA GESTÃO DA MANUTENÇÃO INDUSTRIAL DE UMA EMPRESA DE METAL-MECÂNICA
}

Miguel Afonso Sellitto ${ }^{1}$ Silmar Jose Fachini ${ }^{2}$

\section{RESUMO}

O objetivo deste artigo é analisar a estratégia de gestão da manutenção de uma empresa da indústria metal-mecânica a partir do diagnóstico das manutenções corretivas, preventivas, preditivas e melhorias realizadas na empresa. O método de pesquisa foi o estudo de caso. $\mathrm{O}$ estudo faz uma revisão sobre a aplicação dos recursos de manutenção, apresenta a metodologia de pesquisa, o método de trabalho e os resultados. O método de coleta de dados foi a pesquisa descritiva, que consiste em dados obtidos na própria empresa junto à equipe de manutenção. Constituiuse em um trabalho de levantamento bibliográfico, pesquisa, observação, análise, classificação e interpretação dos dados coletados. A partir de uma amostra de 45 dias, foi possível descrever o cenário das intervenções realizadas pelos mecânicos de manutenção, tendo como resultado a aplicação dos recursos de manutenção na empresa. $\mathrm{O}$ estudo permitiu à empresa ter uma visão geral das manutenções realizadas e, com isso, é possível afirmar que a implantação de uma estratégia de manutenção pode fazer com que o setor de manutenção trabalhe de forma estratégica, com objetivos comuns aos da empresa que, por sua vez, fica melhor preparada para lidar com os constantes desafios de um mercado competitivo.

Palavras-Chave: Manutenção Corretiva. Manutenção Preventiva. Estratégia de Manutenção. 


\section{INTRODUÇÃO}

A economia global atual retrata um mercado cada vez mais competitivo entre as companhias, acompanhada de uma maior demanda e exigência de seus clientes por melhores produtos e serviços. Tal cenário tem impulsionado empresas a buscarem novas formas de gerenciamento que as direcionem para se manterem vivas no mercado, investindo em estudos e aplicações de ferramentas orientadas à melhoria do processo produtivo, levando este a um melhor desempenho técnico e operacional.(KARDEC; NASCIF, 2005).

Partindo dessa análise, uma das formas de se obter maior desempenho e, consequentemente, melhoria no sistema produtivo, está relacionada à implantação de um programa de gestão da manutenção. Fica claro, portanto, a importância dessa atividade dentro do processo produtivo devido à necessidade de as empresas garantirem que a sua produção atenda determinados padrões de qualidade e prazos cada vez mais apertados.

\section{O BOM DESEMPENHO DOS}

\section{EQUIPAMENTOS NO SETOR}

PRODUTIVO REflETE DIRETA-

MENTE NOS RESULTADOS DA

ORGANIZAÇÃO.

Paradas não programadas, porém, geram queda na receita, podendo se converter em prejuízos. Conforme Lafraia (2001), esta afirmação é compreendida ao considerar que o trabalho de manutenção se enobrece a cada dia na busca constante para que se evitem as falhas e não apenas para corrigi-las.
Com a intensificação de uma economia globalizada, houve também um crescimento na demanda por equipamentos e sistemas com melhor desempenho aliado ao baixo custo. Também surgiu a necessidade de redução na probabilidade de ocorrência de falhas nos produtos, considerando que essas falhas podem causar aumento dos custos dos produtos ou até acidentes. Com a análise e minimização dos diversos tipos de falhas, busca-se o aumento da confiabilidade dos equipamentos. (FOGLIATTO; RIBEIRO, 2009).

Conforme Monchy (1989) e Laugeni e Martins (2002), a manutenção dos equipamentos de produção é fundamental para a produtividade das indústrias e para o aumento de sua competitividade. Para que a manutenção cumpra sua missão junto ao processo produtivo, é importante planejamento e controle, considerando a aplicação dos recursos disponíveis, sejam eles técnicos, humanos ou financeiros.

O objetivo técnico da manutenção é o aumento da confiabilidade e da efetiva disponibilidade das plantas. Isso resulta na redução da duração do tempo e na frequência das falhas. O objetivo financeiro é alcançar o objetivo técnico a um custo mínimo. $\mathrm{O}$ custo direto de manutenção é apenas um dos fatores a serem considerados, os outros são representados por custos indiretos, ou seja, os custos de indisponibilidade e/ou degradação de desempenho do sistema. A finalidade da manutenção é a minimização da sua resultante, ou seja, a redução do custo geral de produção. (STEFANINI, 2011).

A manutenção, como função estratégica, tornase responsável pelo gerenciamento da disponibilidade dos ativos e com importância na busca de 
resultados.Esses resultados serão tanto melhores quanto mais eficaz for a gestão da manutenção. Dados da Associação Brasileira de Manutenção (ABRAMAN,2011) mostram que, em 2011,os custos relativos com manutenção no Brasil têm se mantido constantes, com aproximadamente $4 \%$ sobre o faturamento bruto das empresas, e demonstram que elas empregam cerca de $26 \%$ do tempo de trabalho dos seus funcionários de manutenção em ações corretivas. A realidade indica que as organizações devam objetivar melhorias contínuas na gestão da manutenção por meio de conhecimentos inovadores e aplicação de métodos consolidados.

O objetivo deste artigo é identificar e analisar por diagnóstico o cenário das manutenções mecânicas realizadas nas unidades fabris de uma empresa da indústria metal-mecânica, realizada por meio de uma pesquisa do tipo aplicada.
O elevado número de paradas dos equipamentos se reflete no não atingimento das metas de produção.

O método de pesquisa foi o estudo de caso. Os objetivos específicos foram: (i) realizar um diagnóstico identificando onde são aplicados os recursos de manutenção da empresa, por meio de pesquisa realizada com os mecânicos de manutenção; (ii) verificar junto à equipe de manutenção a importância e a aplicabilidade dos requisitos de manutenção; (iii) elaborar um sistema de gestão de manutenção de curto e longo prazo; e (iv) verificar se a estratégia de manutenção está alinhada com a estratégia de produção da empresa.

O restante do artigo está organizado em: revisão bibliográfica, descrição da pesquisa, discussão dos resultados, conclusão, e consideração final.

\section{A MANUTENÇÃO}

Para Tavares (1999), a manutenção gera condições operacionais para que equipamentos, instalações e serviços funcionem adequadamente, com vistas a atingir objetivos e metas da empresa.

A Associação Brasileira de Normas Técnicas (ABNT), através da NBR 5462 de 1994, considera que a manutenção seja uma combinação de ações técnicas e administrativas cujo objetivo seja manter ou recolocar um item no estado em que possa desempenhar a função requerida, o que eventualmente exige modificações de engenharia.

Se antes o objetivo da manutenção era de restaurar as condições originais de um determinado equipamento ou sistema, segundo Kardec e Carvalho (2002), atualmente, a manutenção garante a disponibilidade de funcionamento dos equipamentos e sistemas de maneira a atender o processo produtivo a um custo adequado, com segurança, confiabilidade e preservação do meio ambiente.

Conforme Moubray (2000), a manutenção tem evoluído mais do que outras funções gerenciais, dado o aumento no número, na complexidade e na diversidade de instalações, equipamentos, projetos e sistemas produtivos.

Segundo Mirshawka e Olmedo (1993), um dos principais objetivos da gestão da manutenção moderna é maximizar a disponibilidade dos equipamentos, ao mesmo tempo em que baixa o custo e leva a qualidade, mantendo a segurança e preservando o meio ambiente. 


\subsection{Definição da Manutenção}

Conforme Rosa (2006), é objetivo de atividades de manutenção evitar a degradação de equipamentos, sistemas produtivos e instalações causada pelo desgaste natural de componentes e pelo uso do maquinário. Essa degradação pode ser observada pela aparência externa das máquinas e dos prédios e também pela observação de perdas de desempenho, tais como paradas de produção, entrega de produtos de má qualidade e impactos ambientais. Em sentido mais restrito, atividades de manutenção limitam-se à reposição de equipamentos a estados nos quais possam cumprir sua missão. Em sentido mais amplo, atividades de manutenção podem e devem introduzir melhorias em equipamentos e sistemas.

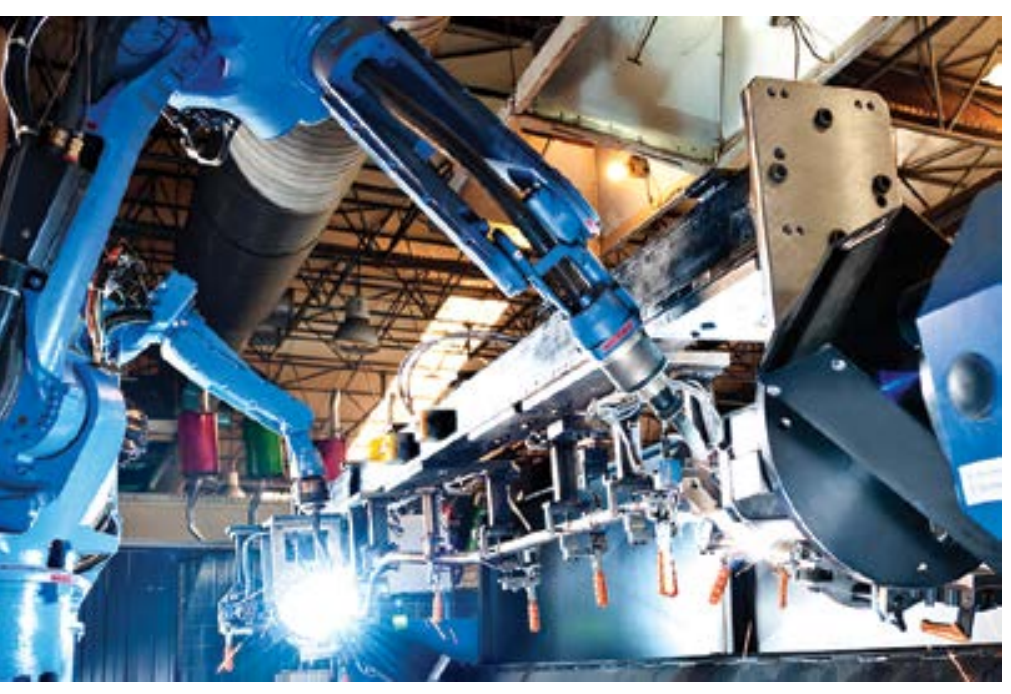

Segundo Tavares (1999), a manutenção engloba as ações e os recursos necessários para que equipamentos mantenham-se nas condições de desempenho originais, como recebidos de fábrica e concebidos na fase de projeto.

Para Xenos (1998), atividades de manutenção podem ter focos distintos. De um lado, observam-se as atividades propriamente ditas, preocupadas em manter as condições originais dos equipamentos. De outro, observam-se atividades de melhoria dos equipamentos que modificam as condições originais de operação, introduzindo novos patamares de produtividade. $\mathrm{O}$ referido autor finaliza seu pensamento considerando um sentido bem mais abrangente para o conceito de manutenção. O objetivo da função não é somente de manter ou até mesmo restaurar as condições físicas dos ativos, mas de também manter suas capacidades funcionais.
A definição de manutenção envolve a obtenção de diversos aspectos objetivos e mensuráveis, tais como disponibilidade, confiabilidade, manutenibilidade, desem- penho operacional do sistema produtivo, entre outros. Seus aspectos essenciais podem e devem ser considerados na estratégia de produção da empresa.

\subsection{A Gestão da Manutenção}

A gestão da manutenção é definida pelas ações tomadas no gerenciamento da parte técnica e do relacionamento na empresa. Ela é estabelecida por meio da condução das atividades de rotina dos serviços e da implementação de melhorias. É importante o monitoramento de todas as atividades envolvidas na manutenção, pois à medida que as atividades de um projeto crescem, as formas pelas quais elas podem causar impacto entre si crescem exponencialmente. (SLACK et al., 2010).

Em sua estrutura, um sistema de gestão de manutenção engloba um conjunto de atividades estrategicamente desenvolvidas e integradas para direcionar a atuação da equipe, visando a atuar na causa dos problemas, antecipandose às quebras. Estabelece e garante um fluxo lógico das informações desde a sua origem até a finalização da execução do serviço. Objetiva a satisfação dos clientes através de um padrão ótimo de prestação de serviço dentro dos recursos existentes. 


\subsection{Métodos de Manutenção}

Os métodos de manutenção indicam de que maneira a intervenção nos equipamentos é realizada. $\mathrm{Na}$ literatura, encontram-se diversas maneiras de classificar os tipos de manutenção. Segundo Zaions (2003), a classificação mais apropriada é a de manutenção não planejada e a planejada.

A manutenção não planejada corrige falhas após a ocorrência e gera perdas de produção, perdas de qualidade do produto e elevados custos.
A manutenção planejada é aquela na qual há diminuição de perda de produção, minimização do custo e do tempo de reparo.

Para Patton (1994), a manutenção planejada pode serdividida em: (i) Manutenção Corretiva; (ii) Manutenção Preventiva; e (iii)Manutenção Por Melhorias. A figura 1 ilustra, além dessa classificação, a subdivisão da Manutenção Preventiva em (i) Manutenção de rotina; (ii) Manutenção Periódica e (iii) Manutenção Preditiva.

\section{Figura 1: Método de Manutenção Planejada}

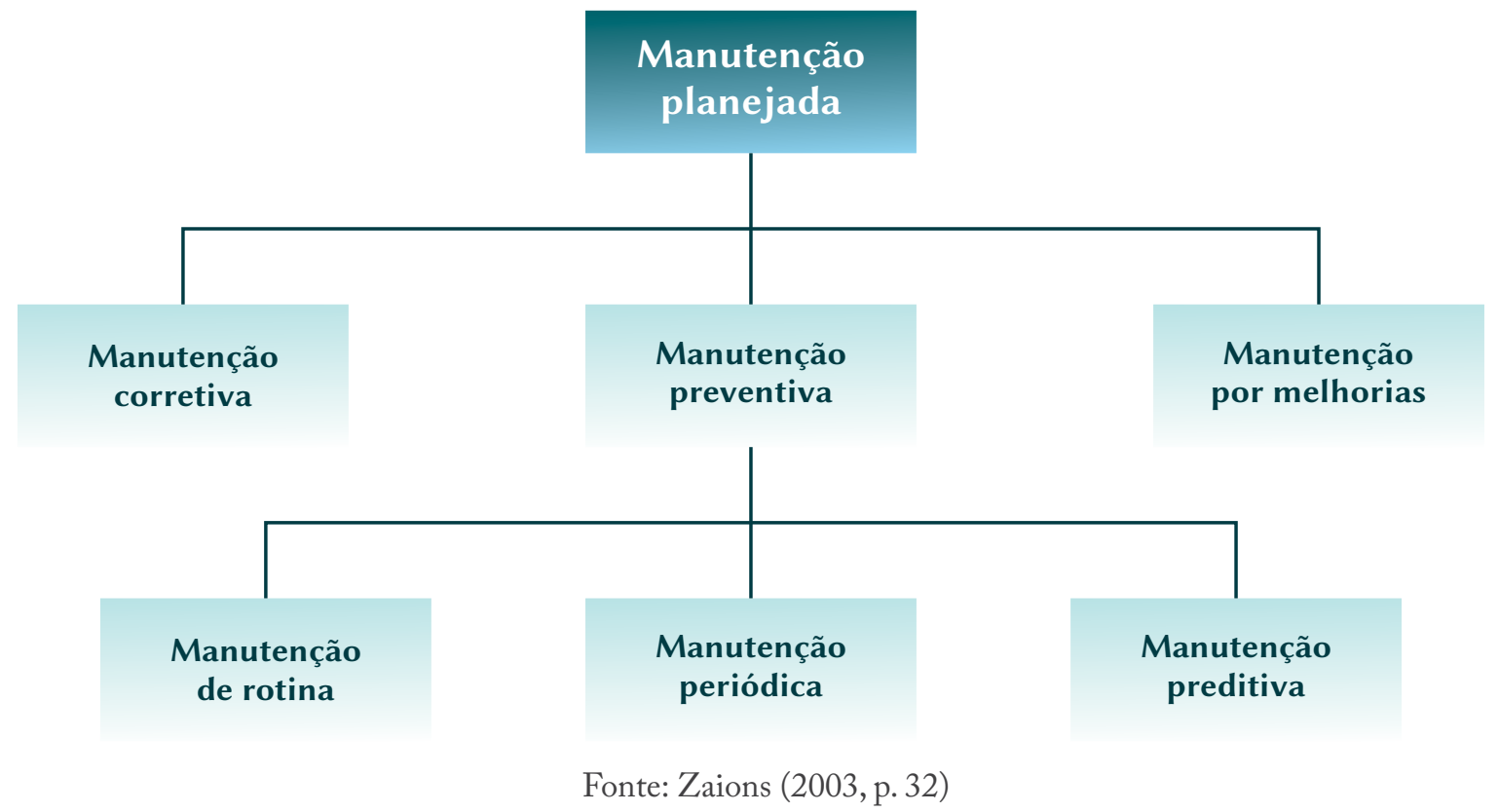

Na manutenção corretiva, os consertos são realizados após a ocorrência de uma falha ou quebra, sendo destinada a recolocar um ou mais itens em condições de executar a função requerida. Segundo Stefanini (2011), a manutenção corretiva tem o objetivo de reparar as quebras inesperadas tão rapidamente quanto possível. Para reduzir o tempo de reparação, de diagnóstico para a máquina retomar a condição de serviço, é necessário ter foco na qualificação do pessoal quando o treinamento e a gestão adequada das peças de reposição irão trazer uma melhor otimização dos recursos.

Conforme Branco Filho (2008), as manutenções corretivas podem ser classificadas em manutenção corretivas programadas, nas quais a correção das falhas ocorre em data posterior ao evento da falha, ficando a máquina em estado de falha até a data do reparo; e também pode ser chamada em manutenção corretiva de emergência quando a manutenção não pode ser adiada e a falha que aconteceu deve ser 
corrigida em seguida. Um aspecto fundamental, mesmo no caso da manutenção corretiva, é o esforço para identificar precisamente as causas fundamentais da falha e bloqueá-las, evitando sua reincidência. (XENOS, 1998).

A manutenção preventiva consiste em atividades de manutenção efetuadas em intervalos prestabelecidos ou determinados de acordo com critérios prescritos, repetidas num intervalo que pode ser definido baseado em tempo de calendário, número de horas trabalhadas, número de partidas de um sistema qualquer. Segundo Monchy (1989), a manutenção preventiva é uma intervenção prevista, preparada e programada antes da data mais provável para o aparecimento da falha. O objetivo final da manutenção preventiva é obter a utilização máxima do equipamento nas tarefas de produção, com a correspondente redução do tempo de máquina parada e custos de manutenção. (ZAIONS, 2003).

O MAIOR DESAfiO PARA QUE A MANUTENÇÃO PREVENTIVA ATINJA SEUS OBJETIVOS É DEfINIR COM QUAL FREQUÊNCIA CADA ATIVIDADE DEVE SER REALIZADA.
Para Stefanini (2011), a manutenção preventiva é realizada de acordo com critérios predeterminados com o objetivo de reduzir a probabilidade de falha de uma planta ou a degradação de um serviço. $\mathrm{O}$ coração do programa é baseado em um calendário de inspeções que é gerado através de ciclos de manutenção preventiva, procedimentos, monitoramento,inspeções,lubrificação e substituição a serem realizados com prazos fixos podendo ser semanal, quinzenal, mensal, trimentral, semestral, anual.

A manutenção de rotina consta de serviços de inspeção e verificações das condições técnicas dos itens físicos. Mirschawka e Olmedo (1993) definem manutenção de rotina como aquela normalmente associada a intervenções leves que se efetua em intervalos de tempos predeterminados. Muitos autores, tais como Xenos (1998) e Lima (2000), tratam a manutenção de rotina como manutenção autônoma. Nesse caso, a responsabilidasde pela manutenção de rotina não é somente do pessoal da manutenção, mas também de todos os operadores e normalmente são executadas no dia a dia para evitar a degradação dos itens físicos.

A manutenção periódica se vale de registros que permitem controles estatísticos de parâmetros importantes para os equipamentos. Pela manutenção periódica, melhora-se a utilização dos equipamentos, dado que a análise estatística permite conhecer mais sobre as falhas nos equipamentos.(POSSAMAI,2002). Segundo Lafraia (2001), a manutenção periódica requer alguma forma de intervenção no item físico. Além do mais, suas ações e sua periodicidade são predeterminadas e ocorrerão sem informações adicionais na data preestabelecida.

A manutenção periódica pode ser definida como a manutenção efetuada em intervalos predeterminados de tempo. Para Lima (2000), o intervalo entre intervenções é definido 
proporcionamente à deterioração do item físico. A intervenção é conduzida no tempo estabelecido,independentemente do estado do componente. A manuteção periódica é realizada com o objetivo de reduzir ou até mesmo eliminar a probabilidade de falha ou de perda de desempenho, segundo um plano prévio, com base em intervalos de tempo ou de outro parâmetro de uso, tais como quilometragens em veículos. (POSSAMAI, 2002).

A manutenção preditiva acompanha e monitora as condições dos equipamentos e de seus principais parâmetros de operação.(BRANCO FILHO, 2008). Destaca-se a intervenção tecnológica que a preditiva exige para o monitoramento, relativamente a equipamento e aparelhos de acompanhamento. A manutenção preditiva pode se valer de controles estatísticos em suas tentativas de predizer a ocorrência de uma quebra ou de corrigir desempenho insatisfatório: constatada a anomalia em andamento, procedese à manutenção. (NASCIF; XAVIER, 2005). Uma intervenção de manutenção preditiva é planejada com base em modificações significativas de parâmetros de condição ou desempenho, cujo acompanhamento obedece a uma sistemática preestabelecida. (SELLITTO, 2005).

Para ser eficiente, a manutenção preditiva deve detectar o mais cedo possível qualquer variação significativa dos parâmetros. Com base nessa variação e em um modelo matemático adequado, calcula-se a probabilidade do equipamento vir a falhar em um horizonte razoável de tempo. Se essa probabilidade for elevada, uma intervenção deve ser programada. (TAVARES, 1999).

Na manutenção por melhorias, os equipamentos são melhorados gradativamente e continuamente, além de suas especificações originais.
Por exemplo, em vez de simplesmente retornar os equipamentos às suas condições originais após a ocorrência das falhas, é preciso melhorar continuamente os equipamentos, alterando, conforme necessário, seu projeto, seus padrões de operação e manutenção. Esse é um dos pontos fracos da manutenção nas empresas brasileiras, onde geralmente a manutenção é considerada completa ao se consertar o defeito e restituir o item à sua condição operacional. (PALMER, 2000).

Palmer (2000) cita que, em algumas organizações, a área de manutenção apenas resolve emergencialmente o problema, ou seja, apenas remove o sintoma da falha, mas não corrige a causa do problema. Já outras organizações treinam os técnicos de manutenção para analisarem as causas da falha na própria ordem de atendimento do problema e, após definirem a causa-raiz, sugerirem melhorias.

Conforme Zaions (2003), a manutenção por melhorias é aplicável quando a vida útil do equipamento é curta, com alta frequência de falhas e alto custo de manutenção, quando o tempo de reparo é elevado e há possibilidade de propagação da falha e quando a dispersão do tempo médio entre falhas é grande, acarretando dificuldades de avaliação e inspeção.

O melhoramento pode também projetar modificações que venham a diminuir o tempo de execução, análise de segurança operacional ou de manutenção, visando a atingir situações de normas e leis, podendo ser chamado de:

a) Reforma (overhaul) - intervenção com troca significativa de partes:

- corrige a degradação do equipamento;

- exige muito tempo para o planejamento. 
b) Modernização (retrofitting) - reforma com troca de tecnologia:

- corrige a inadequação da tecnologia ao objetivo da empresa e envolve troca de subsistemas;

- exige muito tempo para o planejamento.

Entre os tipos de manutenção, uma modalidade não necessariamente será usada para substituir outra, porém pode e deve ser associada a outras, $\mathrm{O}$ que pode trazer resultados satisfatórios segundo uma estratégia de produção. (ZAIONS, 2003).

\subsection{Manutenção Centrada em Confiabilidade (MCC)}

AMCC tem por objetivo garantir a funcionalidade de itens físicos, com uma metodologia essencial no planejamento da manutenção, a partir da estimativa da confiabilidade. Conforme a norma brasileira NBR 5462, item 2.2.6.4, a confiabilidade de um item é a probabilidade de que este item desempenhe a função requerida, por um intervalo de tempo estabelecido, sob condições definidas de uso.

Segundo Fogliatto e Ribeiro (2009), a MCC pode ser definida como um programa que reúne várias técnicas de engenharia para assegurar que os equipamentos de uma planta fabril continuarão realizando as funções especificadas. Devido a sua abordagem sistemática, os programas de MCC têm sido reconhecidos como a forma mais eficiente de tratar as questões de manutenção. Para Xenos (1998), confiabilidade é a probabilidade que um equipamento irá desempenhar satisfatoriamente a sua função, durante um intervalo de tempo especificado sob certas condições predeterminadas.

Cabe à MCC definir requisitos de manutenção necessários para prevenir os modos de falhas que possam causar falhas funcionais de quaisquer itens físicos em seu ambiente operacional.

Segundo Moubray (2000), a MCC é um processo cujo resultado é definir o que deve ser feito para garantir que equipamentos de produção continuem a fazer o que se espera que façam no contexto operacional. Almeida e Souza (2001) definem a MCC como uma sequência de etapas em que são realizadas a divisão e a determinação dos recursos do sistema, a classificação das falhas e interrupções ocorridas e a determinação das atividades de manutenção.

\subsection{Manutenção Classe Mundial (MCM)}

A MCM é a manutenção situada num nível reconhecido dentro das melhores práticas no contexto mundial, com base em parâmetros estabelecidos, por meio de comparação entre as empresas. A análise das práticas e da confiabilidade da manutenção em uma organização é traduzida em índices (indicadores internacionais), e é feita a sua comparação com os índices de companhias líderes no contexto mundial. Para empresas que apresentem desempenho de nível mundial, é necessário que a manutenção também tenha classe mundial. (ABRAMAM, 2011). 


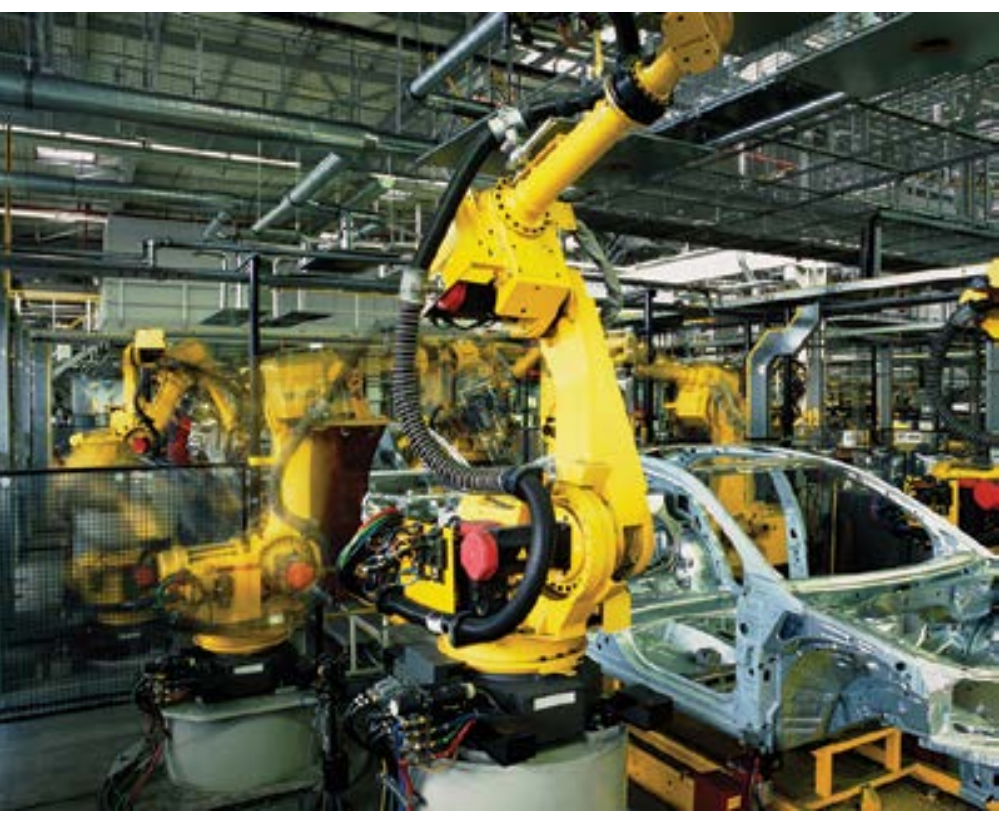

Empresas que ostentem manutenção classe mundial trabalham em equipe, possuem sistemas computadorizados de gerenciamento, realizam manutenção preventiva e preditiva. A manutenção classe mundial é um sistema usado quando a organização combina liderança visionária e coerente com processos robustos e com cultura colaborativa para assegurar que a visão e o senso de propriedade dos métodos de manutenção permeiam por toda a organização. (OTANI; MACHADO, 2008).

\subsection{Custo da manutenção}

Na manutenção, a definição de qualquer curso de ação requer a análise e consideração dos custos envolvidos. Isso implica a necessidade de uma clara explicitação da estrutura de custos, além da apropriação correta desses na estrutura do processo fabril. (SOUZA, 2002).

Para Branco Filho (2008), nenhuma ação de manutenção deve ser tomada se não estiver financeiramente respaldada, considerando os custos de perda de produção, as perdas de matéria-prima, de indenizações por acidentes e poluição ambiental. Ressalta ainda que os custos de manutenção devem ser a principal preocupação de qualquer gerente.

Conforme Kardec e Nascif (2005), os custos de manutenção para fins de controle podem ser classificados em:

- Custos Diretos: são necessários para manter os equipamentos em operação, tais como custos com manutenções preventivas (inspeções, lubrificações etc.), manutenções preditivas, custos de reparos, revisões e manutenção corretiva de uma maneira geral;

- Custosdeperdasde produção:sãooriginados da perda de produção que de outro modo seriavendida,causados pela indisponibilidade dos equipamentos do processo produtivo por falha do equipamento;

- Custos Indiretos: são relacionados a gerenciamento, supervisão, desenvolvimento de projetos, compra de equipamentos de teste ferramental e instrumentação, amortização, depreciação, energéticos e utilidades.

Éimportante montar uma estrutura operacional que possa continuamente apropriar e controlar os custos de manutenção que impactam no processo produtivo. Uma necessidade paralela em todo o contexto onde se pretende implementar uma engenharia de decisão éa existência de um sistema de apoio à decisão sustentado por um sistema de informações gerenciais. (SOUZA, 2002). 


\section{Metodologia}

Esta pesquisa é classificada, quanto à sua natureza, como aplicada, ou seja, os conhecimentos aqui gerados são aplicáveis em uma situação prática. Quanto à forma de abordagem, a pesquisa é classificada como um estudo de caso. No que diz respeito aos objetivos, o método de coleta dos dados foi a pesquisa descritiva, que consiste em dados obtidos na própria empresa junto à equipe de manutenção, analisando o modelo atuale propondo uma nova sistemática baseada nas situações e análises do dia a dia da organização.

Foram coletados os dados de todas as intervenções realizadas pela equipe de manutenção, durante um período de quarenta e cinco dias. As informações foram coletadas toda vez que ocorreram intervenções nas máquinas, sejam elas para realizar uma manutenção corretiva, preventiva, preditiva ou melhoramento. As intervenções foram classificadas conforme o tipo de manutenção realizada e, a partir das análises, foi elaborada uma proposta de gestão de manutenção que irá auxiliar na redução de custos e aumentar a disponibilidade dos equipamentos.

Para verificar se há concordância entre a estratégia de manutenção sugerida e a estratégia de produção da empresa, foram relacionados os objetivos da produção com os tipos de manutenção realizadas. Através de um questionário aplicado a oito gestores de produção com poder de decisão (gerentes de linha), foi solicitado que avaliassem, por julgamento categórico, e colocassem em ordem de importância os seguintes objetivos de produção: (i) redução de custo; (ii) aumento de qualidade; (iii) aumento de pontualidade das entregas; e (iv) aumento da flexibilidade da manufatura. A distribuição de importância segue os dados da tabela 1 .

Tabela 1: Método para distribuir a importância dos objetivos de produção

\begin{tabular}{c|c}
\hline Posição & Pontuação \\
\hline Mais importante & 10 pontos \\
Segundo em importância & 7 pontos \\
Terceiro em importância & 3 pontos \\
Menos importante & 1 ponto \\
\hline
\end{tabular}

Fonte: Dos autores (2014)

Pretende-se contribuir para o desenvolvimento da ciência na área da gerência da manutenção industrial. Entender e explicitar a interligação dos vários fatores que representam a capacidade da manutenção de uma empresa e sua implicação no desempenho empresarial é motivo de atenção e estudo. Já a pesquisa se justifica na medida em que permite estudar a influência desses fatores na procura do diferencial competitivo perante os concorrentes.

Delimitou-se como objetivo principal realizar uma análise e um diagnóstico das manutenções realizadas na empresa e, através da gestão da manutenção, de seus princípios e suas técnicas, propor uma sistemática para realização das manutenções, constituindo em critérios que venham contribuir para decisão dos gestores na aplicação dos recursos de manutenção disponíveis. 


\section{ANÁLISE DE RESULTADOS}

Ao longo de 45 dias, foram mapeadas todas as intervenções realizadas pelos seis mecânicos de manutenção da empresa, a fim de poder criar um histórico, identificando onde estão sendo aplicados os recursos de manutenção, bem como quantificar os de maior incidência. As máquinas envolvidas são um parque robótico de produção de utensílios domésticos e de cutelaria e linhas transfer de abastecimento de matérias-primas e de remoção de roduto acabado. $\mathrm{O}$ período de pesquisa foi suficiente para retratar a realidade estudada.As intervenções de manutenção eram registradas em tabela entregue aos mecânicos, identificando o tipo de manutenção e o tempo de máquina parada.

A partir dos registros das atividades realizadas, foi criado o cenário das intervenções, servindo para classificar por tipo e quantidade de manutenção realizada em cada unidade fabril, conforme a tabela 2 .

Tabela 2: Total de intervenções realizadas em cada unidade fabril

\begin{tabular}{l|c|c|c|c}
\hline \multicolumn{1}{c|}{ Unidades } & $\begin{array}{c}\text { Manutenção } \\
\text { Corretiva }\end{array}$ & $\begin{array}{c}\text { Manutenção } \\
\text { Preventiva }\end{array}$ & $\begin{array}{c}\text { Manutenção } \\
\text { Preditiva }\end{array}$ & $\begin{array}{c}\text { Manutenção por } \\
\text { Melhorias }\end{array}$ \\
\hline Baixelas & 254 & 12 & 18 & 126 \\
\hline Talher & 450 & 55 & 40 & 132 \\
\hline Panelas & 62 & 17 & 24 & 12 \\
\hline Armazém & 1 & 15 & 3 & 645 \\
\hline Total & 767 & 99 & 85 & $40,41 \%$ \\
\hline Porcentagem & $48,06 \%$ & $6,20 \%$ & $5,33 \%$ & 12 \\
\hline
\end{tabular}

Fonte: Dos autores (2014)

Percebe-se, por meio da tabela 2, que 48,06\% das intervenções realizadas pelos mecânicos de manutenção são corretivas, enquanto 6,20\% são de manutenção preventiva, 5,33\% de manutenção preditiva e 40,41\% de manutenção por melhorias.
A cada intervenção realizada foi registrado o tempo utilizado na realização das manutenções criando, assim, o cenário de aplicação dos recursos de manutenção na empresa, conforme tabela 3. 
Tabela 3: Tempo (hs) utilizado em cada tipo de manutenção realizada

\begin{tabular}{l|c|c|c|c}
\hline \multicolumn{1}{|c|}{ Unidades } & $\begin{array}{c}\text { Manutenção } \\
\text { Corretiva }\end{array}$ & $\begin{array}{c}\text { Manutenção } \\
\text { Preventiva }\end{array}$ & $\begin{array}{c}\text { Manutenção } \\
\text { Preditiva }\end{array}$ & $\begin{array}{c}\text { Manutenção por } \\
\text { Melhorias }\end{array}$ \\
\hline Baixelas & 810,6 & 36 & 19 & 876,8 \\
\hline Talher & 784,9 & 244,6 & 52,5 & 1822 \\
\hline Panelas & 118,2 & 78,6 & 24 & 940,8 \\
\hline Armazem & 0,5 & 42,5 & 3,5 & 243,9 \\
\hline Total (Horas) & 1714,2 & 410,7 & 99 & 3883,5 \\
\hline Porcentagem & $28,11 \%$ & $6,59 \%$ & $1,62 \%$ & $63,68 \%$ \\
\hline
\end{tabular}

Fonte: Dos autores (2014)

A tabela 3 também traz o percentual de tempo utilizado na realização de cada tipo de manutenção. A manutenção por melhoria é a que ocupa a maior parte do tempo disponível dos mecânicos de manutenção 63,68\%,em seguida vem a manutenção corretiva com $28,11 \%$,após, a manutenção preventiva com $6,59 \%$ e por fim a manutenção preditiva com $1,62 \%$.

Os tempos utilizados pela empresa para manutenção preventiva e preditiva são somente os recursos utilizados pelos mecânicos de manutenção da empresa. Existe uma parcela da manutenção preventiva e preditiva que corresponde ao operador de cada máquina. Dependendo do equipamento,realiza-se a manutenção semanalmente, quinzenal, mensal, trimestral ou anual.

Observa-se, no gráfico 1, a aplicação dos recursos disponíveis na área de manutenção de cada unidade fabril da empresa, conforme dados levantados na pesquisa.

Gráfico 1: Aplicação dos recursos de manutenção nas unidades da empresa

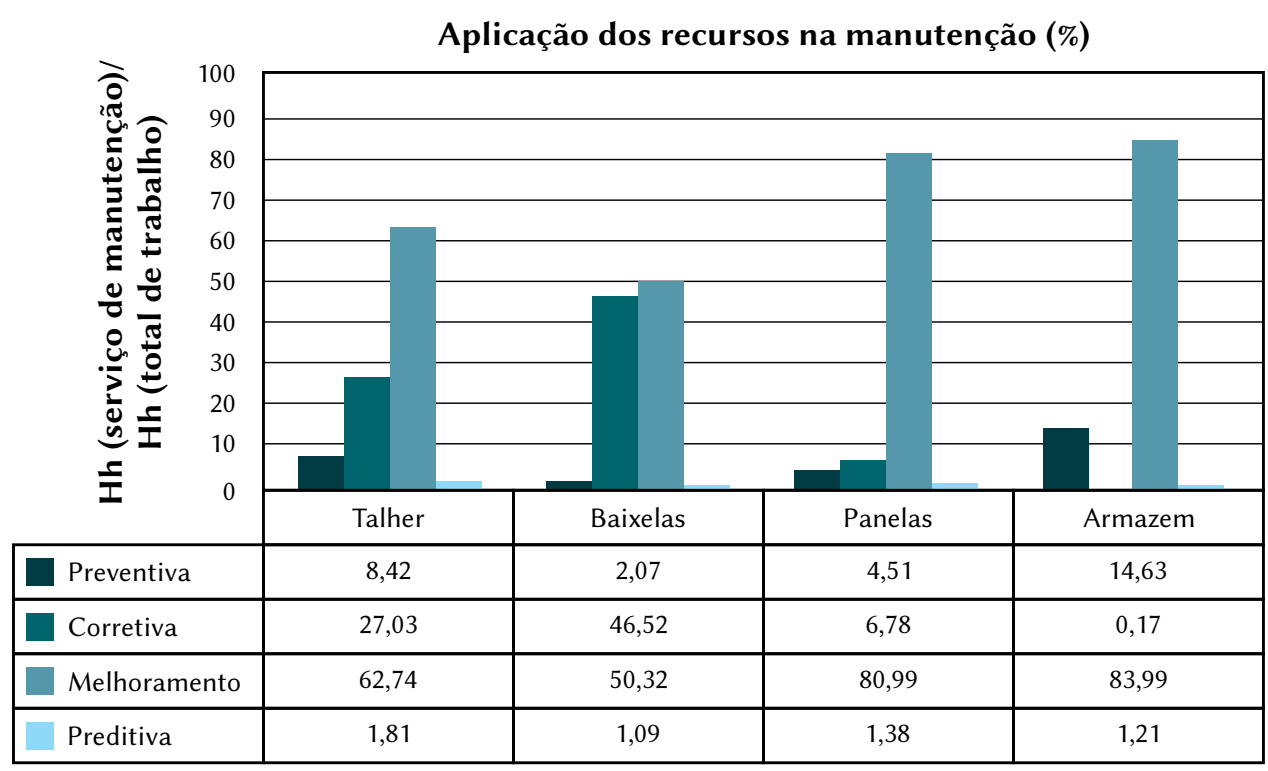

Fonte: Dados da pesquisa interna 
No gráfico 2, observa-se a comparação do cenário geral da aplicação dos recursos de manutenção da empresa com os dados da Associação Brasileira de Manutenção (ABRAMAN, 2011), cujo objetivo é melhorar o padrão de manutenção executado no Brasil.

Segundo dados da ABRAMAN (2011), as grandes empresas do Brasil aplicam 37,17\% dos recursos de manutenção em manutenção preventiva, 27,4\% em manutenção corretiva, $18,51 \%$ em manutenção preditiva e 16,92\% em outros recursos. A comparação dos dados da empresa pesquisada com os dados das empresas que participaram da pesquisa ABRAMAM (2011), é válida pois essas empresas têm equipamentos similares e são do ramo metalúrgico tais como empresas: siderúrgicas, automotivas, de energia eletrica, prestadores de serviços.

Gráfico 2: Comparação dos recursos de manutenção da empresa com a Abraman

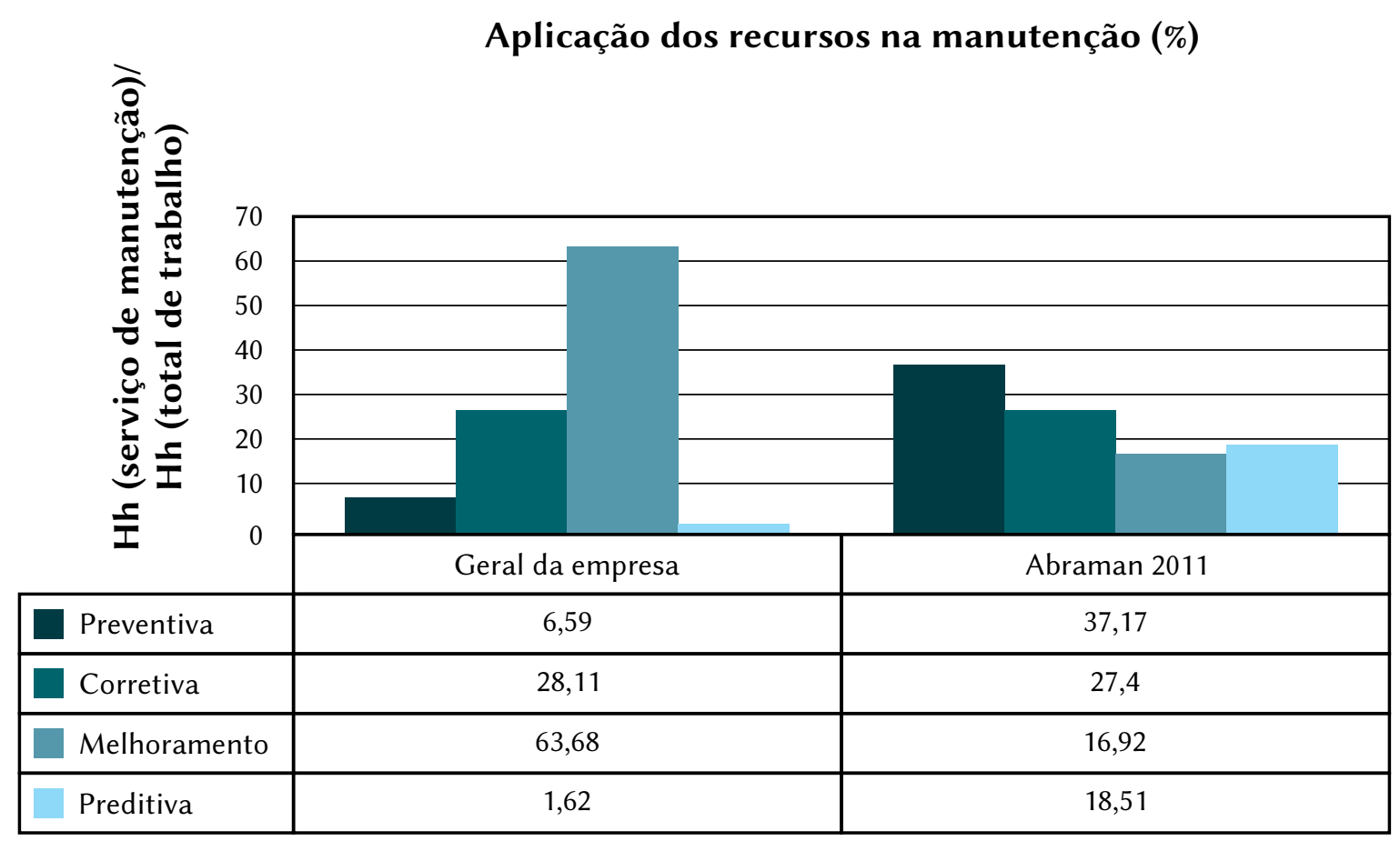

Fonte: Dados da pesquisa interna e dados da Abraman (2011)

Pode ser observado no gráfico 2 que os recursos de manutenção preventiva e preditiva aplicados na empresa são muito inferiores quando comparados com as grandes empresas do Brasil. $\mathrm{Na}$ manutenção corretiva, estamos com um indicador próximo; na manutenção por melhoria, temos um indicador muito acima do que é praticado nas empresas que participaram da pesquisa da Abraman (2011). Este dado deve ter influenciado nos recursos de manutenção utilizados em manutenções corretivas, pois com um baixo indicador de manutenção preventiva e preditiva temos um indicador de manutenção corretiva muito próximo quando comparado com as empresas que participaram da pesquisa Abraman (2011).

Para verificar se há concordância entre a estratégia de manutenção e a estratégia de produção da empresa, foi aplicada uma pesquisa a gestores de produção, solicitando que avaliassem de forma categórica e colocassem em ordem de 
importância os objetivos de produção. Na tabela 4, observam-se os objetivos de produção mais usualmente observados e os tipos de manutenção mais adotados na empresa. $\mathrm{Na}$ tabela, cada linha apresenta o tipo de manutenção mais adequado e que mais se alinha a cada objetivo de produção. Por exemplo, se o objetivo de produção é reduzir custo, a manutenção de emergência é a mais adequada, pois é a que determina menor custo de operação, mesmo que acarrete outras implicações. (SELLITTO, 2005; SELLITTO et al., 2002).

No gráfico 3, observa-se o percentual de cada tipo de manutenção segundo a ordem
Tabela 4: Relação dos objetivos de produção com os tipos de manutenção

\begin{tabular}{l|l}
\multicolumn{1}{c|}{ Objetivos de Produção } & $\begin{array}{c}\text { Tipo de } \\
\text { Manutenção }\end{array}$ \\
\hline Reduzir o custo & Corretiva \\
Aumentar a qualidade & Preditiva \\
Aumentar a pontualidade das & Preventiva \\
entregas & Melhorias \\
Aumentar a flexibilidade da & Manufatura
\end{tabular}

Fonte: Dos autores (2014)

de importância que os gestores de produção deram aos objetivos da produção.

Gráfico 3: Ordem de importância das manutenções para os gestores

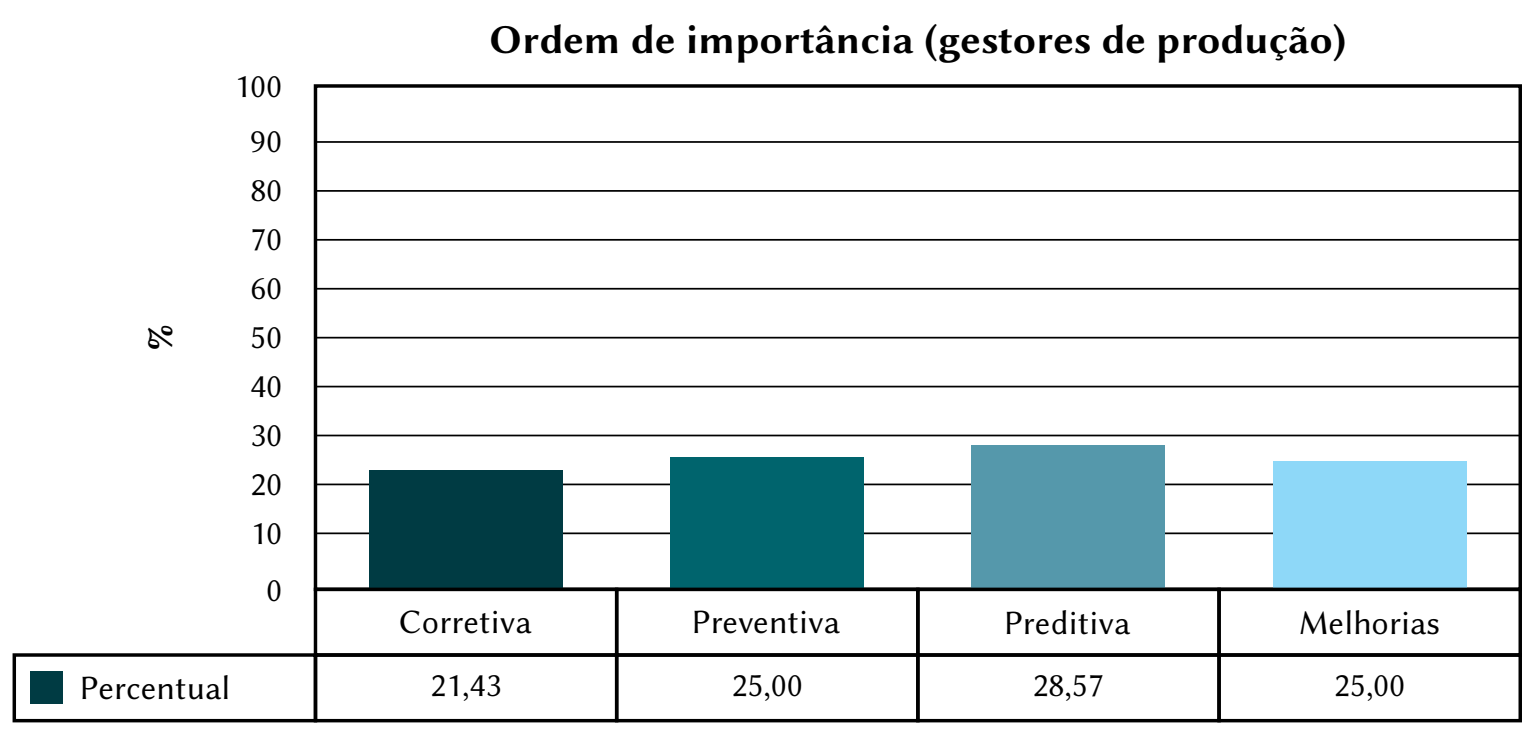

Fonte: Dados da pesquisa realizada com os gestores da produção

Segundo os gestores de produção, a melhor estratégia de manutenção está, respectivamente, em: manutenção preditiva $(28,57 \%)$; manutenção preventiva (25,00\%); manutenção por melhorias $(25,00 \%)$; e manutenção corretiva $(21,43 \%)$. 


\subsection{Ações de curto e longo}

\section{prazo}

O diagnóstico realizado mostrou que, para um resultado eficaz, os recursos aplicados em manutenção preventiva $(6,59 \%)$ são baixos. Foi realizado um levantamento no sistema de manutenção preventiva da empresa e constatou-se que havia um grande número de equipamentos sem registros de manutenção preventiva. Realizou-se uma reunião com os coordenadores da empresa e ficou definido que cada um ficaria responsável em elaborar o plano de manutenção preventiva nos equipamentos correspondente a sua unidade fabril.

$\mathrm{O}$ indicador de manutenção corretiva $(28,11 \%)$ mostrou-se levemente acima ao que é aplicado nas grandes empresas do Brasil (27,4\%), mas considerado alto pelos autores deste trabalho. Uma das maneiras de baixar esse indicador é aumentando o percentual de manutenção preventiva nos equipamentos que são essenciais para as linhas de produção.
Em longo prazo, haverá a necessidade de se implantar na empresa um plano de manutenção preditiva pois, conforme dados do gráfico 2, ela está sendo pouco aplicada até agora. Recomenda-se a manutenção preditiva em todo equipamento gargalo ou crítico, ou seja, aquele cuja falha interrompe a produção, como definido em Sellitto (2002) para atividades industriais. Tal recomendação pode inclusive reduzir custos com outras modalidades, tais como corretiva e preventiva. Assim, recomenda-se também a capacitação da equipe de manutenção da empresa, de forma que os colaboradores tenham mais conhecimento técnico, visto que é fundamental para a elaboração, a execução e o acompanhamento da estratégia de manutenção adotada.

\section{Conclusão}

CONCLUIU-SE QUE A MELHOR

ESTRATÉGIA DE MANUTENÇÃO

PARA A EMPRESA ESTÁ EM MAN-

TER UM EQUILÍBRIO ENTRE OS

TIPOS DE MANUTENÇÕES QUE

SÃO REALIZADAS. e dar continuidade com as manutenções de melhorias. Assim diminuem-se as manutenções corretivas, antecipando falhas e reduzindo perdas.

Diante dos dados apresentados, fica claro que a estratégia atual de manutenção está desalinhada com a estratégia de produção.

Esse resultado é consistente com a ordem de importância que os gestores de produção deram aos tipos de manutenções realizadas na empresa, com base nas estratégias de produção.

Para isso, precisa-se aumentar a quantidade de equipamentos com manutenção preventiva, focar mais na manutenção preditiva por meio da implantação de um programa estruturado, 
As preferências dos gestores são equilibradas, todas próximas de $25 \%$, enquanto que a prática de manutenção é desequilibrada: cerca de 1,6\% dos recursos de manutenção são aplicados em manutenção preditiva e 63,6\% em manutenção por melhorias. Com a implementação de um programa de manutenção preditiva, esperase que ocorra a diminuição das manutenções corretivas, aumentando a disponibilidade dos equipamentos para o atendimento das metas de produção (86\%) na empresa, gerando menos custos com manutenção.

Um ponto que deve ser analisado no gráfico 2 é o quanto a empresa aplica dos seus recursos de manutenção $(63,68 \%)$ em manutenção de melhoramento. Aqui os equipamentos são melhorados gradativamente e continuamente, alterando, conforme necessário, seu projeto, seus padrões de operação e manutenção. Segundo Palmer (2000), esse é um dos pontos fracos da manutenção nas empresas brasileiras, onde geralmente a manutenção é considerada completa ao se consertar o defeito e restituir o item à sua condição operacional.

As perdas e as ineficiências são como uma fábrica escondida, ou seja, existem mais recursos instalados do que realmente utilizados. É de importância salientar que, apesar da economia gerada pelo não acompanhamento e medidas preventivas sobre o equipamento, na manutenção corretiva as máquinas podem quebrar durante o funcionamento, ocasionando paradas na produção e outros prejuízos, tais como: necessidade de se trabalhar com estoques; necessidade de grande mobilização pela parada inesperada; danos maiores no maquinário devido a falhas graves. Empresas que possuem equipamentos caros e que paradas em sua linha de produção são prejudiciais ao seu desempenho devem tomar medidas a fim de minimizar ao máximo a possibilidade de ocorrência de falhas ocasionadas por falta ou manutenção inadequada. 
STRATEGIC

ANALYSIS OFTHE

MANAGEMENT

OF INDUSTRIAL

MAINTENANCE OF A

METAL-MECHANICAL

COMPANY

\section{REFERÊNCIAS}

ALMEIDA, A.; SOUZA, F. Gestão da manutenção: na direção da competitividade. Recife: Ed. Universitária da UFPE, 2001.

ABRAMAN. Associação Brasileira de Manutenção, Documento Nacional 2011. Disponível em: <http://www.abraman.org.br>. Acesso em: 30 maio 2013.

ASSOCIAÇÃO BRASILEIRA DE NORMAS TÉCNICAS. NBR 5462: Confiabilidade e Mantenabilidade. Rio de Janeiro, 1994.

BRANCO FILHO, G. A Organização, o Planejamento e o Controle da Manutenção. Rio de Janeiro: Editora Ciência Moderna LTDA., 2008.

FOGLIATTO, F.; RIBEIRO J. Confiabilidade e manutenção Industrial. Rio de Janeiro: Elsevier, 2009.

KARDEC, A.; NASCIF, J. Manutenção Função Estratégica. Rio de Janeiro: Qualitymark Editora Ltda, 2005.

KARDEC, A.; CARVALHO, C. Gestão Estratégica e Terceirização. Rio de Janeiro: Qualitymark, 2002.

LAFRAIA, J. Manual de Confiabilidade, Mantenabilidade e Disponibilidade. Rio de Janeiro: Qualitmark, 2001.

LAUGENI, F.; MARTINS, P. Administração da Produção. São Paulo: Saraiva, 2002.

LIMA, R. TPM Total Productive Maintenance - Curso de Formação de Multiplicadores. Belo Horizonte: Advanced Consulting e Training, 2000.

MIRSHAWKA, V.; OLMEDO, N. Manutenção - Combate aos Custos da Não-Eficácia: A vez do Brasil. São Paulo: Editora Makron Books do Brasil, 1993.

MONCHY, F. A Função Manutenção Formação para a Gerência da Manutenção Industrial. São Paulo: Editora Durban, 1989.

MOUBRAY, J. Manutenção Centrada em Confiabilidade. São Paulo: Aladon Ltda, 2000.

OTANI, M.; MACHADO, W. A proposta de desenvolvimento de gestão da manutenção industrial na busca da excelência ou classe mundial. Gestão Industrial, v.4, n.2, p.1-16, 2008.

PALMER, D. Maintenance Planning and Scheduling Handbook. New York: McGraw-Hill, 2000. 
PATTON, J. Maintainabiliy and Maintenance Management. New York: Instrument Society of America, 1994.

POSSAMAI, R. A implantação da metodologia TPM num equipamento piloto na Adria Alimentos do Brasil Ltda. 2002, XX f. Dissertação (Mestrado em Engenharia de Produção). UFRGS, Rio Grande do Sul, 2002.

ROSA, E. Indicadores de Desempenho e Sistema ABC o Uso de Indicadores para uma Gestão Eficaz do Custo e das Atividades de Manutenção. 2006, xx f. Tese (Doutorado em Engenharia), Escola Politécnica da Universidade de São Paulo, 2006.

SELLITTO, M. Formulação estratégica da manutenção industrial com base na confiabilidade dos equipamentos. Produção, v.15, n.1, p.044-059, 2005.

SELLITTO, M. Inteligência artificial: uma aplicação em uma indústria de processo contínuo. Gestão \& Produção, v.9, n.3, p.363-376, 2002.

SELLITTO, M.; BORCHARDT, M.; ARAÚJO, D. Manutenção centrada em confiabilidade: aplicando uma abordagem quantitativa. Anais do XXII ENEGEP, Encontro Nacional de Engenharia de Produção. Curitiba: ABEPRO, 2002.

SLACK, N, HARRISON, A.; HARLAND, C.; JOHNSTON, R.; CHAMBERS, S. Administração da produção. São Paulo: Atlas, 2010.

SOUZA, F. Decisões racionais em situações de incerteza. Recife: Ed. Universitária da UFPE, 2002.

STEFANINI, P. Metodi di Ricerca e

Prevenzione dei Guasti. Milano: Tecniche Nuove II Edizione, 2011.

TAVARES, L. Excelência na Manutenção Estratégias, otimização e Gerenciamento. Salvador: Casa da Qualidade, 1999.

XENOS, H. Gerenciando a Manutenção Produtiva. Belo Horizonte: Editora de Desenvolvimento Gerencial, 1988.

ZAIONS, D. Manutenção Industrial com Enfoque na Manutenção Centrada em Confiabilidade. Porto Alegre: UFRGS, 2003. Dissertação (Mestrado em Engenharia), Curso de Pós Graduação em Engenharia de Produção, Universidade Federal do Rio Grande do Sul, 2003.

\section{SOBRE OS AUTORES}

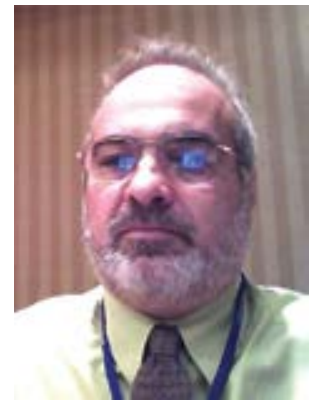

Miguel Afonso Sellitto

Doutor e Mestre em

Engenharia de Produção pela

Universidade Federal do Rio

Grande do Sul (UFRGS).

Especialista em Gestão da

Qualidade pela Unisinos.

Graduado em Engenharia Eletrônica pela UFRGS. É professor de mestrado e doutorado e pesquisador do Programa de Pós-Graduação em Engenharia de Produção e Sistemas na Universidade do Vale do Rio dos Sinos (Unisinos). Pesquisador do CNPq. Possui aperfeiçoamentos importantes em manutenção,gestão e produção na Inglaterra, Estados Unidos eJapão. Tem vinte anos de experiência executiva em grandes empresas e é consultor em manutenção, produção, estratégia e logística.

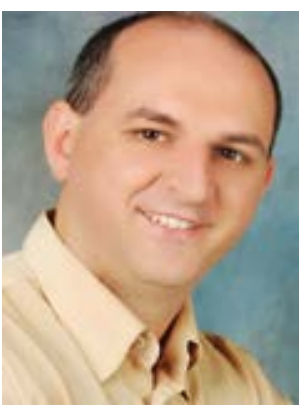

\section{Silmar Jose Fachini}

Especialista em Engenharia de Produção e Sistemas pela Universidade do Vale do Rio dos Sinos (Unisinos) e graduado em engenharia mecânica pela Universidade de Caxias do Sul (UCS). Possui experiência na área industrial no segmento metalmecânico, atuando como Ferramenteiro de corte, supervisor dos setores de Estamparia e de Mecânica. Tem conhecimentos em desenvolvimento de novos produtos, trabalhos focados em resultados de equipe e bom relacionamento. Atualmente é supervisor da área de manutenção e desenvolvimento de novos produtos na empresa Tramontina Farroupilha S.A. 